Cite this: RSC Adv., 2014, 4, 12840

Received 7th January 2014 Accepted 20th February 2014

DOI: 10.1039/c4ra00132j

www.rsc.org/advances

\section{Kurahyne, an acetylene-containing lipopeptide from a marine cyanobacterial assemblage of Lyngbya sp. $\dagger$}

\author{
Arihiro Iwasaki, ${ }^{a}$ Osamu Ohno, ${ }^{a}$ Shinpei Sumimoto, ${ }^{\text {b }}$ Shoichiro Suda ${ }^{b}$ \\ and Kiyotake Suenaga*a
}

Kurahyne, a new acetylene-containing lipopeptide, was isolated from a cyanobacterial assemblage that mostly consisted of Lyngbya sp. Its structure was elucidated by spectroscopic analyses and chiral HPLC analyses of hydrolysis products. Kurahyne inhibited the growth of human cancer cells and induced apoptosis in HeLa cells, and it seemed to localize in mitochondria.

Some peptides derived from marine organisms have attracted attention due to their remarkable bioactivities. ${ }^{1}$ Marine cyanobacteria, in particular, produce a variety of novel lipopeptides. ${ }^{2}$ In our continuing search for new bioactive substances from marine cyanobacteria, ${ }^{3}$ we investigated the constituents of a cyanobacterial assemblage that mostly consisted of Lyngbya sp. collected at Okinawa, Japan, and isolated an acetylene-containing lipopeptide, kurahyne (1). Structurally, 1 contains a C8-alkynoate moiety and a C7-ketone moiety. The same C8-alkynoate unit has only been found in dragonamide $\mathrm{E},{ }^{\mathbf{4}}$ and the same $\mathrm{C} 7$-ketone unit has only been found in bisebromoamides. ${ }^{5}$ Kurahyne (1) was found to inhibit the growth of human cancer cells and to induce apoptosis in HeLa cells.

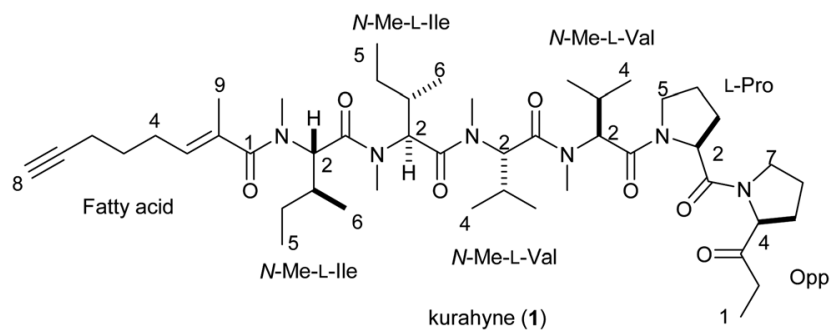

${ }^{a}$ Department of Chemistry, Keio University, 3-14-1, Hiyoshi, Kohoku-ku, Yokohama, Kanagawa 223-8522, Japan. E-mail: suenaga@chem.keio.ac.jp

${ }^{b}$ Faculty of Science, University of Ryukyus, 1 Senbaru, Nishihara, Okinawa 903-0213, Japan

$\dagger$ Electronic supplementary information (ESI) available: ${ }^{1} \mathrm{H},{ }^{13} \mathrm{C}$, COSY, NOESY, HMQC, HMBC and INEPT NMR spectra in $\mathrm{C}_{6} \mathrm{D}_{6}$ for kurahyne (1). IR spectrum. HPLC chromatograms for determination of absolute configurations. Detailed experimental procedures. See DOI: 10.1039/c4ra00132j
The marine cyanobacterial samples ${ }^{6}(2.3 \mathrm{~kg}$, wet weight $)$ were collected at Kuraha, Okinawa, and were extracted with methanol. The extract was filtered, concentrated, and partitioned between EtOAc and $\mathrm{H}_{2} \mathrm{O}$. The EtOAc-soluble material was further partitioned between $90 \%$ aqueous $\mathrm{MeOH}$ and hexane. The material obtained from the aqueous $\mathrm{MeOH}$ portion was subjected to fractionation with reversed-phase column chromatography (ODS silica gel, $\mathrm{MeOH}-\mathrm{H}_{2} \mathrm{O}$ ) and reversed-phase HPLC (Cosmosil Cholester, MeCN- $\mathrm{H}_{2} \mathrm{O}$; Cosmosil 5C $\mathrm{C}_{18}$-MS-II, $\left.\mathrm{MeOH}-\mathrm{H}_{2} \mathrm{O}\right)$ to give kurahyne (1) $(29.9 \mathrm{mg})$ as a colorless oil. The molecular formula of 1 was found to be $\mathrm{C}_{47} \mathrm{H}_{78} \mathrm{~N}_{6} \mathrm{O}_{7}$ by HRESIMS $\left(m / z\right.$ 839.5991, calcd for $\mathrm{C}_{47} \mathrm{H}_{79} \mathrm{~N}_{6} \mathrm{O}_{7}[\mathrm{M}+\mathrm{H}]^{+}$ 839.6010). The NMR data for 1 are summarized in Table 1.

The ${ }^{1} \mathrm{H}$ NMR spectrum revealed the presence of four singlets corresponding to $N$-methyl amide substituents $(\delta 3.38,3.27,3.26$, 2.86 ), one vinyl methyl group ( $\delta 1.75)$, five methine groups corresponding to the $\alpha$ position of the amino acid residue $(\delta 5.54$, $5.53,5.49,5.40,4.50)$ and nine high-field methyl groups $(\delta 1.22$, $0.96,0.94,0.92,0.90,0.86,0.86,0.79,0.77)$. Additionally, the ${ }^{1} \mathrm{H}$ NMR spectrum indicated an olefinic double triplet ( $\delta 5.38)$ and a triplet characteristic of a terminal acetylene proton $[\delta 1.80(\mathrm{~J}=2.9$ $\mathrm{Hz})$ ]. 1 possessed two ${ }^{13} \mathrm{C}$ NMR absorptions consistent with a terminal acetylene ( $\delta 83.8$ and 69.4), and seven carbonyl signals $(\delta$ 208.5, 173.4, 170.91, 170.88, 170.6, 170.3, 169.2). Further analysis of the ${ }^{1} \mathrm{H}$ NMR, ${ }^{13} \mathrm{C}$ NMR, COSY, HMQC and HMBC spectra revealed the presence of proline, two $N$-methylvalines and two $N$-methylisoleucines. Additionally, the presence of residues derived from 2-(1-oxo-propyl)-pyrrolidine (Opp) and 2-methyloct2-en-7-ynoic acid (fatty acid) was also established. Despite the presence of a terminal acetylene, an IR band of triple bond stretching was not observed (see ESI, S10 $\dagger$ ). The existence of an acetylene group was confirmed based on the magnitude of the coupling constant of C-8 of fatty acid $\left({ }^{1} J_{\mathrm{C}-\mathrm{H}}=253 \mathrm{~Hz}\right)$ on the INEPT spectrum (see ESI, S8 and 9†) and comparison of the ${ }^{13} \mathrm{C}$ chemical shifts between 1 and dragonamide $\mathrm{E}^{4}$ possessing the same fatty acid moiety (see ESI, S20†).

The sequence of these partial structures was determined based on HMBC and NOESY data (Table 1 and Fig. 1). A NOESY 
Table 1 NMR Data for kurahyne (1) in $\mathrm{C}_{6} \mathrm{D}_{6}{ }^{2}$

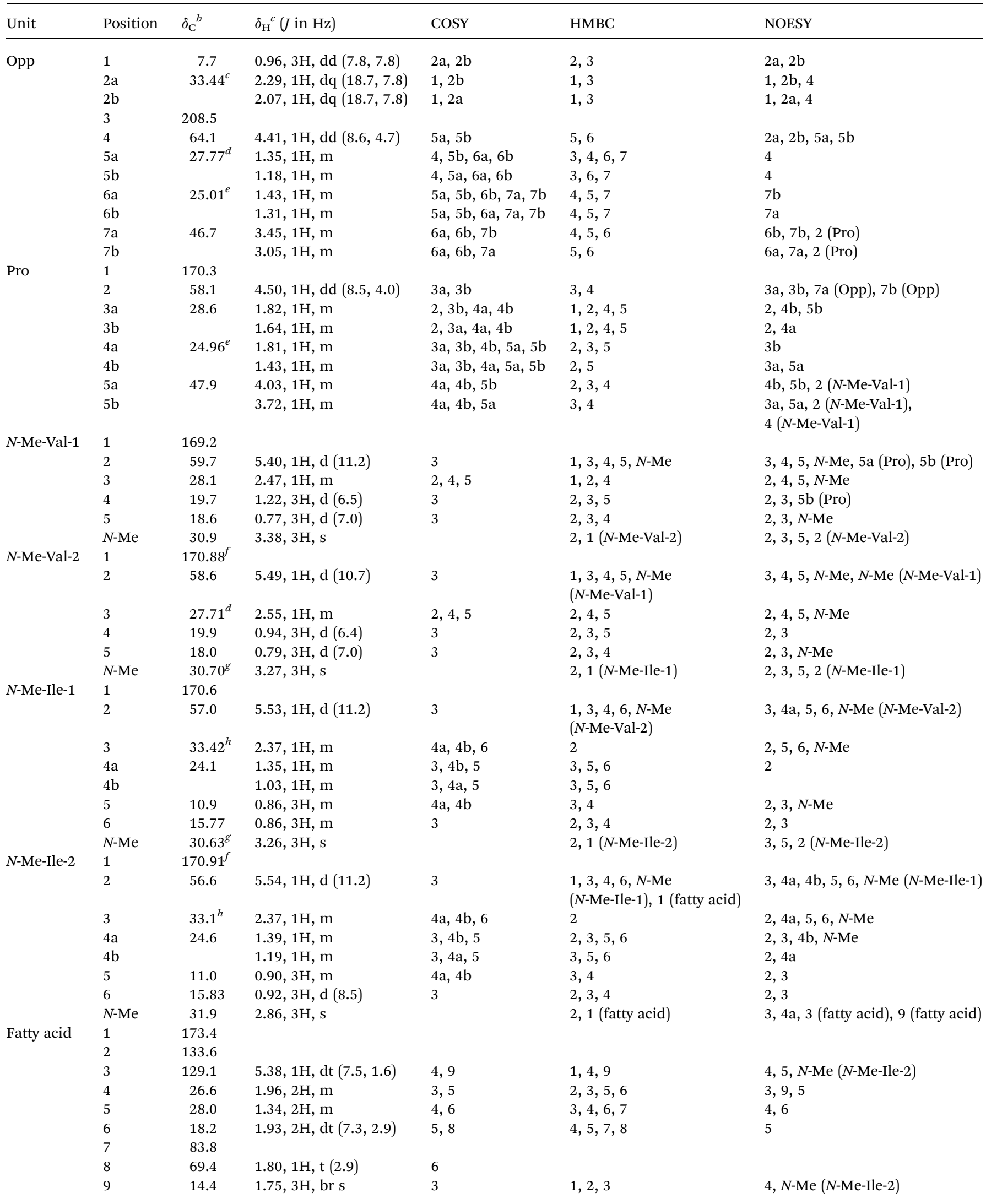

${ }^{a}{ }^{1} \mathrm{H}^{13} \mathrm{C}$ connectivities were determined by HMQC method. ${ }^{b}$ Measured at $100 \mathrm{MHz} .{ }^{c}$ Measured at $400 \mathrm{MHz} .{ }^{d}$ These carbon signals are interchangeable, respectively. ${ }^{e}$ These carbon signals are interchangeable, respectively. ${ }^{f}$ These carbon signals are interchangeable, respectively. ${ }^{g}$ These carbon signals are interchangeable, respectively. ${ }^{h}$ These carbon signals are interchangeable, respectively. 


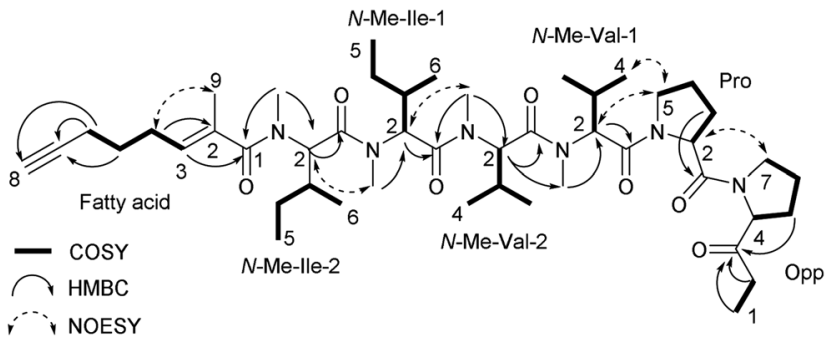

Fig. 1 Established structure of kurahyne (1), based on 2D NMR correlations.

correlation between $\mathrm{H}-7$ of Opp and $\mathrm{H}-2$ of Pro connected these two residues. Two NOESY correlations observed at $\mathrm{H}-5$ of $\mathrm{PrO} / \mathrm{H}-$ 2 of $N$-Me-Val- 1 and $\mathrm{H}-5 \mathrm{~b}$ of Pro/H-4 of $N$-Me-Val- 1 revealed the connectivity between these two residues. Additional HMBC correlations, $\mathrm{H}-2$ of $N$-Me-Val-2/N-Me of $N$-Me-Val- 1 and $N$-Me of $N$-Me-Val-2/C- 1 of $N$-Me-Ile-1, and NOESY correlations, $N$-Me of $N$-Me-Val-2/H-2 of $N$-Me-Ile- 1 and $N$-Me of $N$-Me-Ile- $1 / \mathrm{H}-2$ of $N$-Me-Ile-2, expanded the sequence to Opp-Pro- $N$-Me-Val- $N$-MeVal- $N$-Me-Ile- $N$-Me-Ile. Furthermore, an HMBC correlation at $N$-Me of $N$-Me-Ile-2/C-1 of fatty acid allowed us to determine the location of the fatty acid moiety. Finally, NOESY correlations, $\mathrm{H}-4$ of fatty acid/H-9 of fatty acid, and the chemical shift of the vinyl methyl carbon ( $\delta 14.4$, C-9 of fatty acid) supported an $E$ geometry for the $\mathrm{C} 2-\mathrm{C} 3$ olefinic bond in the fatty acid moiety, thereby completing the gross structure of kurahyne, as shown in Fig. 1.

To assign the absolute configurations of the eight chiral centers, we generated optically active fragments. Enantiomeric standards for Pro are commercially available, while those for other moieties must be synthesized in the laboratory by standard methods ( $N$-Me-Val, $N$-Me-Ile, Opp). ${ }^{7}$ According to the previous paper, ${ }^{5 a}$ a direct acid hydrolysis of an Opp-containing compound resulted in the epimerization of $\mathrm{C}-4$ of the Opp moiety. To prevent the racemization of Opp, reduction of the ketone with $\mathrm{NaBH}_{4}$ followed by acid hydrolysis afforded every amino acid component contained in $\mathbf{1}$ and 2-(1-hydroxypropyl)-pyrrolidine derived from an Opp moiety as a mixture of two diastereomers. Based on a comparison of the retention times of the obtained amino acids to those of authentic samples by chiral HPLC, all of the amino acid components in $\mathbf{1}$ were determined to be $\mathrm{L}$-form. With regard to the Opp moiety, the absolute configuration was determined by reversed-phase HPLC analysis based on a comparison of the retention times of Marfey derivatives ${ }^{8}$ of the obtained diastereomeric alcohols to those of authentic samples. As a result of the analysis, the absolute configuration of the Opp moiety was elucidated to be $4 S$. The absolute stereochemistry of kurahyne was determined as shown in $\mathbf{1 .}$

To evaluate the growth-inhibitory activities of kurahyne (1), an MTT assay with HeLa cells and HL60 cells was used. The cells were treated in 96-well plates with various concentrations of the compounds (0.01-10 $\mu \mathrm{g} \mathrm{mL} \mathrm{mL}^{-1}$ for HeLa cells, $0.001-10 \mu \mathrm{g} \mathrm{mL}$ for HL60 cells) for $72 \mathrm{~h}$. The data from these assays revealed that 1 inhibited the growth of both HeLa cells and HL60 cells, with $\mathrm{IC}_{50}$ values of $3.9 \pm 1.1 \mu \mathrm{M}$ and $1.5 \pm 0.1 \mu \mathrm{M}$, respectively. Additionally, 1 showed cytotoxicity against HeLa cells, as
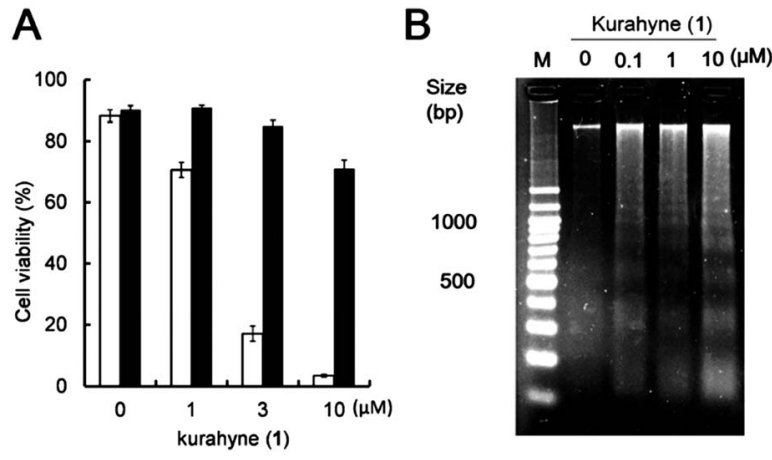

Fig. 2 Induction of apoptosis caused by kurahyne (1) in HeLa cells. (A) HeLa cells were preincubated (solid column) or not (open column) with $50 \mu \mathrm{M}$ of Z-VAD-FMK. They were then treated with the indicated concentrations of 1 . After further incubation for $48 \mathrm{~h}$, cell viability was determined. Values are the mean \pm SD of quadruplicate determinations. (B) HeLa cells were incubated with the indicated concentrations of 1 for $36 \mathrm{~h}$. Cellular DNA was then extracted and electrophoresed on agarose gels.
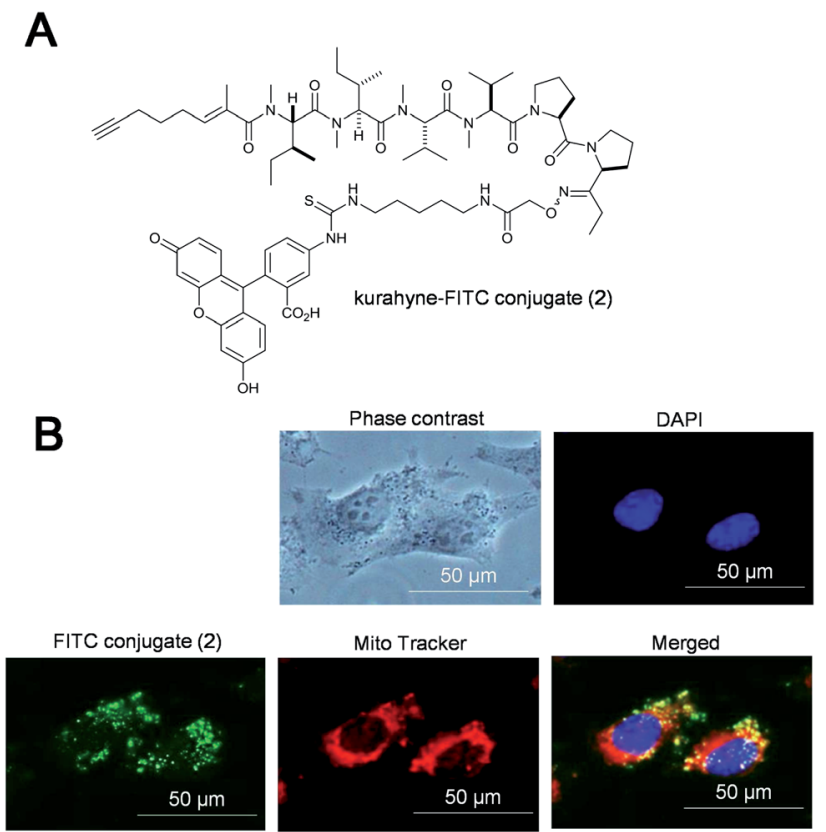

Fig. 3 Subcellular localization of kurahyne-FITC conjugate (2) in HeLa cells. (A) Chemical structure of 2. (B) Fluorescence micrograph of treated HeLa cells. Cells were incubated with $10 \mu \mathrm{M}$ of 2 for $10 \mathrm{~h}$. Mitochondria and nuclei were visualized with Mito Tracker (red) and DAPI (blue), respectively. Conjugate 2 (green) and Mito Tracker were observed to colocalize.

determined using the trypan blue dye exclusion assay. Furthermore, cell death of these cells induced by 1 was suppressed in the presence of Z-VAD-FMK, an irreversible and cell-permeable inhibitor of caspases (Fig. 2A). Significant DNA laddering in these cells was observed in the presence of 1 (Fig. 2B). These results indicated that $\mathbf{1}$ induced apoptosis in HeLa cells. To examine the subcellular localization of $\mathbf{1}$, a kurahyne-fluorescein conjugate 2 was synthesized (Fig. 3A). Introduction of fluorescein to $\mathrm{COOH}$-terminus of kurahyne retained 
its growth inhibitory activity ( $\mathrm{IC}_{50}: 85 \pm 13 \mu \mathrm{M}$, HeLa cells). The staining sites of 2 seemed to be included in those of Mito Tracker Red in HeLa cells on the basis of fluorescence microscopic analysis (Fig. 3B). From this result, it is likely that the mechanism of action of $\mathbf{1}$ is mitochondrially-targeted.

In conclusion, kurahyne (1), a novel acetylene-containing lipopeptide, was isolated from a marine cyanobacterial assemblage that mostly consisted of Lyngbya sp. The structure of 1 was established by spectroscopic analysis and HPLC analysis of acid hydrolysates. The structural features of $\mathbf{1}$ are the presence of an Opp moiety and a 2-methyloct-2-en-7-ynoic acid moiety. To our knowledge, $\mathbf{1}$ is the first reported compound which possesses both of these moieties. 1 inhibited the growth of both HeLa cells and HL60 cells, with $\mathrm{IC}_{50}$ values of $3.9 \pm 1.1 \mu \mathrm{M}$ and $1.5 \pm 0.1$ $\mu \mathrm{M}$, respectively. Furthermore, 1 was revealed to induce apoptosis in HeLa cells, and it seemed to localize in mitochondria. The detailed bioactive investigation of $\mathbf{1}$ is ongoing.

\section{Acknowledgements}

This work was supported in part by Grants-in-Aid from the Ministry of Education, Culture, Sports, Science and Technology of Japan (24310160 and 25750386) and the MEXT-Supported Program for the Strategic Research Foundation at Private Universities, 2009-2013 from the Ministry of Education, Culture, Sports, Science and Technology, Japan.

\section{Notes and references}

1 L. H. Zheng, Y. J. Wang, J. Sheng, F. Wang, Y. Zheng, X. K. Lin and M. Sun, Mar. Drugs, 2011, 9, 1840-1859.

2 (a) M. Tanighchi, J. K. Nunnery, N. Engene, E. Esquenazi, T. Byrum, P. C. Dorrestein and W. H. Gerwick, J. Nat. Prod., 2010, 73, 393-398; (b) H. Choi, A. R. Pereira, Z. Cao, C. F. Shuman, N. Engene, T. Byrum, T. Matainaho,
T. T. Murray, A. Mangoni and W. H. Gerwick, J. Nat. Prod., 2010, 73, 1411-1421; (c) E. Mevers, T. Byrum and W. H. Gerwick, J. Nat. Prod., 2013, 76, 1810-1814.

3 (a) A. Iwasaki, T. Teruya and K. Suenaga, Tetrahedron Lett., 2010, 51, 959-960; (b) T. Teruya, H. Sasaki, K. Kitamura, T. Nakayama and K. Suenaga, Org. Lett., 2009, 11, 24212424; (c) M. Morita, O. Ohno, T. Teruya, T. Yamori, T. Inuzuka and K. Suenaga, Tetrahedron, 2012, 30, 5984-5990.

4 M. J. Balunas, R. G. Linington, K. Tidgewell, A. M. Fenner, L. D. Ureña, G. D. Togna, D. E. Kyle and W. H. Gerwick, J. Nat. Prod., 2010, 73, 60-66.

5 (a) T. Teruya, H. Sasaki, H. Fukazawa and K. Suenaga, Org. Lett., 2009, 11, 5062-5065; (b) H. Sasaki, T. Teruya, H. Fukazawa and K. Suenaga, Tetrahedron, 2011, 67, 990-994.

6 The most cyanobacterium was morphologically classified into the genus Lyngbya because it was composed of short cells with a thick sheath. From the phylogenetic tree inferred from 959 bp of 16S rRNA gene sequences (see ESI, S16 †) revealed that the present cyanobacterium (Maeda 130904A, accession no. AB857842) formed a clade with Oscillatoria miniata NAC8-50 (GU724208), and closely related with Trichodesmium spp. ${ }^{9}$ The identification described above was carried out using the same cyanobacterium collected at the same location in September 2013, and we confirmed that its extract contained 1. Despite our efforts, other minor cyanobacteria in the assemblage were not identified by $16 \mathrm{~S}$ rRNA gene analysis. A detailed classification will be reported later.

7 X. Gao, Y. Liu, S. Kwong, Z. Xu and T. Ye, Org. Lett., 2010, 12, 3018-3021.

8 P. Marfey, Carlsberg Res. Commun., 1984, 49, 591596.

9 (a) S. Suda, R. Moriya, S. Sumimoto, O. Ohno and K. Suenaga, J. Mar. Sci. Tech., 2013, 21, 175-180; (b) A. Iwasaki, S. Sumimoto, O. Ohno, S. Suda and K. Suenaga, Bull. Chem. Soc. Jpn., DOI: 10.1246/bcsj.20140008. 